\title{
Influence of molecular weight on the phase behavior and structure formation of branched side-chain hairy-rod polyfluorene in bulk phase
}

\author{
M. Knaapila, ${ }^{1, *}$ R. Stepanyan, ${ }^{2}$ M. Torkkeli, ${ }^{3}$ B. P. Lyons, ${ }^{1}$ T. P. Ikonen, ${ }^{3}$ L. Almásy, ${ }^{4}$ J. P. Foreman, ${ }^{1}$ R. Serimaa, ${ }^{3}$ \\ R. Güntner, ${ }^{5}$ U. Scherf, ${ }^{5}$ and A. P. Monkman ${ }^{1}$ \\ ${ }^{1}$ Department of Physics, University of Durham, South Road, Durham DH1 3LE, United Kingdom \\ ${ }^{2}$ Department of Applied Physics, University of Twente, P.O. Box 217, 7500 AE Enschede, The Netherlands \\ ${ }^{3}$ Department of Physical Sciences, P.O. Box 64, FI-00014, University of Helsinki, Finland \\ ${ }^{4}$ Research Institute for Solid State Physics and Optics, P.O. Box 49, Budapest-1525, Hungary \\ ${ }^{5}$ Makromolekulare Chemie und Institut für Polymertechnologie, Bergische Universität Wuppertal, D-42097, Wuppertal, Germany
}

(Received 28 October 2004; published 15 April 2005)

\begin{abstract}
We report on an experimental study of the self-organization and phase behavior of hairy-rod $\pi$-conjugated branched side-chain polyfluorene, poly[9,9-bis(2-ethylhexyl)-fluorene-2,7-diyl]-i.e., poly[2,7-(9,9-bis(2ethylhexyl)fluorene] $(\mathrm{PF} 2 / 6)$ —as a function of molecular weight $\left(M_{n}\right)$. The results have been compared to those of phenomenological theory. Samples for which $M_{n}=3-147 \mathrm{~kg} / \mathrm{mol}$ were used. First, the stiffness of $\mathrm{PF} 2 / 6$, the assumption of the theory, has been probed by small-angle neutron scattering in solution. Thermogravimetry has been used to show that PF2/6 is thermally stable over the conditions studied. Second, the existence of nematic and hexagonal phases has been phenomenologically identified for lower and higher $M_{n}$ (LMW, $M_{n}<M_{n}^{*}$ and HMW, $M_{n}>M_{n}^{*}$ ) regimes, respectively, based on free-energy argument of nematic and hexagonal hairy rods and found to correspond to the experimental x-ray diffraction (XRD) results for PF2/6. By using the lattice parameters of PF2/6 as an experimental input, the nematic-hexagonal transition has been predicted in the vicinity of glassification temperature $\left(T_{g}\right)$ of PF2/6. Then, by taking the orientation parts of the free energies into account the nematic-hexagonal transition has been calculated as a function of temperature and $M_{n}$ and a phase diagram has been formed. Below $T_{g}$ of $80^{\circ} \mathrm{C}$ only (frozen) nematic phase is observed for $M_{n}<M_{n}^{*}=10^{4} \mathrm{~g} / \mathrm{mol}$ and crystalline hexagonal phase for $M_{n}>M_{n}^{*}$. The nematic-hexagonal transition upon heating is observed for the HMW regime depending weakly on $M_{n}$, being at $140-165{ }^{\circ} \mathrm{C}$ for $M_{n}>M_{n}^{*}$. Third, the phase behavior and structure formation as a function of $M_{n}$ have been probed using powder and fiber XRD and differential scanning calorimetry and reasonable semiquantitative agreement with theory has been found for $M_{n} \geqslant 3 \mathrm{~kg} / \mathrm{mol}$. Fourth, structural characteristics are widely discussed. The nematic phase of LMW materials has been observed to be denser than high-temperature nematic phase of HMW compounds. The hexagonal phase has been found to be paracrystalline in the $(a b 0)$ plane but a genuine crystal meridionally. We also find that all these materials including the shortest 10-mer possess the formerly observed rigid five-helix hairy-rod molecular structure.
\end{abstract}

DOI: 10.1103/PhysRevE.71.041802

PACS number(s): 36.20.-r, 82.35.Lr, 64.60.Cn, 61.10.Eq

\section{INTRODUCTION}

The general guidelines for the phase behavior of simple mesomorphic macromolecules are well established (see, e.g., [1-5]). In contrast, the design of self-organized structures [6] and the understanding of nanoscale [7] structure-property relationships remain key issues in the research of $\pi$-conjugated polymers. These polymers are typically sc hairy-rod-like materials [8-11] consisting of a rigid or wormlike backbone where a dense set of side chains is bonded in a comb-shaped manner, resulting characteristically in liquid crystallinity (LC). Their mesomorphic behavior may be understood recognizing them as a specific type of block copolymers [4] that tend to form microphase separated structures: Bare rigid molecules may form a lyotropic phase but the rod coils with long enough segments self-organize to a thermotropic phase where the flexible and rigid parts microphase separate. The

*Author to whom correspondence should be addressed. Electronic address: matti.knaapila@durham.ac.uk block copolymers consisting of flexible backbone and rigid side chains [12] reveal mesomorphism, too, but it is the rigidity of the backbone that is the molecular vehicle controlling the electronic properties such as the dielectric function [13] or triplet energies [14] of $\pi$-conjugated polymers. Although the structural tailoring of archetype hairy rods, such as $\operatorname{poly}(\alpha$, L-glutamate) [15], is far advanced, the work on $\pi$-conjugated hairy rods is less comprehensive. Substituted poly(p-phenylene)s (PPP's) [16-18] and poly(alkylthiophenes) (PAT's) [19-21] yet represent archetypes where hairy-rod structure leads to self-organization with enhanced electronic characteristics [22,23].

Among $\pi$-conjugated hairy rods, poly(2,7-fluorenes) (PF's) [24] have emerged as the most promising materials for applications. As a rule they exhibit LC, rendering facile uniaxial orientation which results in the emission of linearly polarized light, when used in polarizing light-emitting diodes (LED's) [25], and increase mobility when utilized in thinfilm transistors (TFT's) [26,27]. Altogether their chemical and molecular structure [24], intermolecular selforganization [28], overall alignment [26], and larger-scale 
morphology in films and at interfaces $[29,30]$ as well as thermal history [31,32] and casting solvent [33] determine their optoelectronic performance and should be optimized in a concerted manner.

Apart from PF's with linear side chains, especially poly(9,9-(di- $n, n$-octylfluorene)) (PF8) [34,35], a branched side chain poly(9,9-bis(2-ethylhexyl)-fluorene-2,7-diyl) (PF2/6) $[36,37]$ is particularly interesting. Its simple chemical structure and excellent stability allow its straightforward use as a theoretical and experimental model molecule in structural work. Yet it is far more than a structural "model," revealing high hole-transport mobility and high photoluminescence (PL) and electroluminescence (EL) quantum yields. Emission in the blue region of the spectrum, tunable by energy transfer to dopants [38-40], and facile overall alignment put forward its use in thin-film devices such as polarized $[29,36,41]$ or all-polymeric white LED's [40]. PF2/6 is important also from the fundamental photophysical point of view showing, e.g., measurable long-lived electrophosphorescence and delayed EL at low temperature [42]. The structure of PF2/6 has been studied by Lieser et al. [43] who found that PF2/6 is a five-helical molecule with hexagonal phase. The structure-temperature relation of PF2/6 is currently being studied by Tanto et al. [32] who find that PF2/6 is disordered after synthesis but annealing up to the glass transition temperature $\left(T_{g}\right)$ initiates the structure towards the hexagonal phase and that the annealing-cooling cycle greatly improves the crystallite size while optical spectroscopy resolves subtle changes. These authors also find both 5/2- and 5/1-helices energetically possible and the side chains disordered and perpendicular to the helices.

The molecular weight $\left(M_{n}\right)$ is known to influence the structure formation of $\pi$-conjugated hairy rods such as PPP [18]. The effect of $M_{n}$ of poly(3-octylthiophene) [44] or poly(3-hexylthiophene) (P3HT) [45,46] in TFT's, poly $(9,9-$ dioctylfluorene-co-benzothiadiazole) (F8BT) in photovoltaic devices [47], or PF8 in LED's [48,49] has been studied. These reports deal with $M_{n}$ of PF from the optoelectronic performance point of view, whereas Papadopoulos et al. [50] reported the influence of $M_{n}$ on the molecular dynamics and glass transition of PF8 and analogous oligomers and Banach et al. [51] that on thermotropic alignment of F8BT. These authors used a $M_{n}$ range of $M_{n}=62-129 \mathrm{~kg} / \mathrm{mol}$ and concluded that the degree of alignment is a function of $M_{n}$ and limited both by viscosity and, in particular, by the formation of an equilibrium (macroscopic) multidomain structure [51]. On the other hand, we have recently studied the structure formation of PF2/6 [52-54] and found a hexagonal phase in axially and in-plane aligned thin films [52] for high- $M_{n}$ $\mathrm{PF} 2 / 6\left(M_{n}=147 \mathrm{~kg} / \mathrm{mol}\right)$ and a considerable increase in the degree of alignment accompanied by the loss of order in the (ab0) plane, a nematic phase, for low- $M_{n} \mathrm{PF} 2 / 6\left(M_{n}\right.$ $=7.6 \mathrm{~kg} / \mathrm{mol}$ ) [53-55]. Like F8BT [51], in these films the $\mathrm{PF} 2 / 6$ chains are parallel to the substrate in the $\mathbf{z}$ direction corresponding to the rubbing direction of the under layer polyimide. However, high- $M_{n}$ PF2/6 reveals two kinds of coexistent hexagonal crystallites, where the greater proportion of the crystallites have one crystal axis a perpendicular to the substrate surface, whereas a smaller proportion is aligned with the crystal axis a parallel to surface. Similar phenomena in $\pi$-conjugated polymers have been found only for stretch-aligned poly( $p$-phenylenevinylene) (PPV) [56] and in-plane aligned P3HT [22,57]. In addition, monoaxial distributions, sc inverse combs have been found for PAT's [58]. In order to clarify these peculiarities of PF2/6 in detail in thin films there is a clear need to systematically study the influence of $M_{n}$ to the phase behavior of PF2/6 starting from the bulk.

In this paper, we present an experimental study of phase behavior of PF2/6 as a function of $M_{n}$ using a large $M_{n}$ range $M_{n}=2.9-147 \mathrm{~kg} / \mathrm{mol}$ and compare the results to phenomenological theory argument. First, the nematic and hexagonal phases, for phenomenological "low" and "high" $M_{n}$, respectively, have been theoretically identified based on freeenergy considerations in the equilibrium state. These phases have been observed to correspond to our previous qualitative x-ray diffraction (XRD) observation [53]. Second, the nematic-hexagonal transition has been calculated as a function of $M_{n}$ and $T$, completing the theoretical semiquantitative phase diagram. In the vicinity of $T_{g}\left(\sim 80^{\circ} \mathrm{C}\right)$, the nematichexagonal transition as a function of $M_{n}$ is seen at $M_{n}^{*}$ $=10^{4} \mathrm{~g} / \mathrm{mol}$. Upon heating the nematic-hexagonal transition is observed at $140-165^{\circ} \mathrm{C}$ for $M_{n}>M_{n}^{*}$. The predicted phase behavior and structure formation have been probed using powder XRD and differential scanning calorimetry (DSC) and reasonable semiquantitative agreement with theory has been found. In addition, thermogravimetry (TGA) and small-angle neutron scattering (SANS) have been used to probe stability and stiffness, the presumptions of the theory. TGA shows that PF2/6 is thermally stable in studied conditions. SANS measurement indicates that $\mathrm{PF} 2 / 6$ takes a rodlike conformation of the polymer $\left(M_{n}=92 \mathrm{~kg} / \mathrm{mol}\right)$ for $1-11 \mathrm{mg} / \mathrm{ml}$ solutions which is in agreement with the result in dilute concentration $(1.7 \mathrm{mg} / \mathrm{ml})$ obtained by Fytas et al. [59]. The results of the powder XRD are compared to those of fiber XRD and all these materials, including the shortest decamer molecule, are found to reveal the previously found five-helix hairy-rod molecular structure with typical lattice parameters of $a=16.67 \AA$, and $c=40.40 \AA$, and $c=39.5 \AA$ for hexagonal and nematic phases, respectively. The hexagonal phase has been found to be paracrystalline and locally highly ordered, revealing a coherence length of at least $300 \AA$ A, while the nematic phase shows primarily meridional order. These results form a quantitative framework on how to use $M_{n}$ as a tuning parameter for the phase behavior of $\mathrm{PF} 2 / 6$ in bulk and form a basis for understanding how $M_{n}$ influences the thermotropic alignment of PF2/6 in films (see in our parallel study [60]). Unlike Banach et al. [51] who used a copolymer (because of their interest in the good electron transport properties of F8BT), we use a simple hairy rod and therefore the results may more easily give general guidelines to other hairy rods.

\section{THEORY}

The hairy-rod-like polymers [11] can be discussed using concepts borrowed from the theory of copolymers [61,62], an approach for which a reasonable experimental resem- 


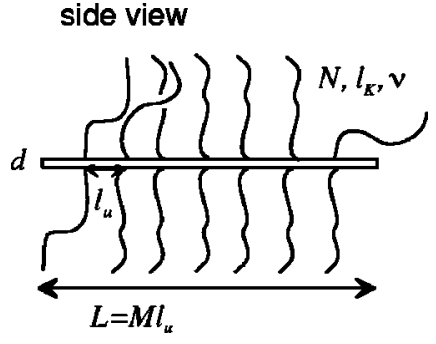

FIG. 1. Schematics of a hairy-rod polymer consisting of stiff backbone and flexible covalently connected side chains. $N, l_{K}$, and $v$ are the number of segments, the segment length (the Kuhn length), and the volume of the beds of the side chains, respectively; $M, l_{u}, L$, and $d$ are the number of the repeat units, distance between grafting points (the unit length), and the length and diameter of the rod, respectively.

blance has been found [63]. Here we apply this treatment further. The model used in theory is depicted in Fig. 1. We consider a melt of monodisperse rigid rods of length $L$ and diameter $d$, assuming $L \gg d$, and the side chains that are assumed to consist of $N$ beads of volume $\nu$ and a statistical segment length $l_{K}$. The ideal coil size is $R_{c}=l_{K} \sqrt{N} \ll L$. $M$ denotes the number of repeat units of the backbone so that $M_{n}=M_{u} M$, where $M_{u}$ is the molecular weight of one repeat unit. PF2/6 is of course not exactly rigid and therefore its stiffness is probed using SANS in Sec. IV below. The bending of PF2/ 6 can be further addressed but this is not essential in semiquantitative considerations.

Instead of focusing on derivation of the free energies, we will refer to the existing literature on the subject $[61,62]$ and focus our attention on the essence of the physics behind the phenomena which have been experimentally observed and presented in this paper. We primarily consider nanometerscale intermolecular structure formation, putting less attention on the chemical details and intramolecular order, and denote the nanometer-scale order as "local," making a distinction to the overall alignment and macroscopic morphology. This is the level where the theory is assumed to give reasonable predictions.

In this scheme we have previously shown that hairy rods (Fig. 1) can form a large number of both theoretically [61,62] and experimentally [63] observed phases, but when considering PF2/6 as a function of $M_{n}$, two main options, nematic and hexagonal, are of particular interest. These phases are illustrated in Fig. 2.

The peculiarities of the transition from the nematic into hexagonal phase of the hairy rods may be understood on the basis of a simple analysis partially presented in our previous publication [53]. In the nematic-hexagonal transition the

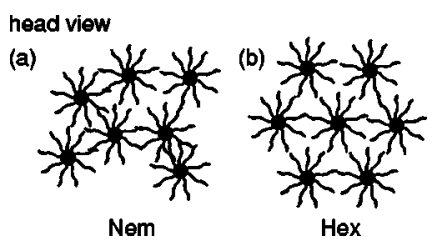

FIG. 2. End-on schematics of (a) nematic (Nem) and (b) hexagonal (Hex) phase of hairy-rod molecules. hairy-rod-like molecules lose their translational freedom, but reduce the interaction free energy when the molecules are fixed in the lattice positions, and we may employ an analysis based on the comparison between the free energies of the observed phases. The free energy of the nematic phase has been estimated as $[53,61,62]$

$$
F_{N} \approx k_{B} T V c \ln \frac{f}{e}+k_{B} T V c \ln \frac{4 \pi}{\Omega_{N}},
$$

where the first and second terms, respectively, correspond to the translational and orientational entropies. Here $k_{B} T$ is a Boltzmann factor, $V$ volume of the sample, $c$ concentration of hairy-rod molecules, $f$ the volume fraction of the backbone in the molecule, and $e$ the Euler number. The quantity $\Omega_{N}$ describes the degree of overall (uniaxial) alignment: The smaller it is, the more aligned the system obtained.

The hexagonal phase is characterized by negligibly small translational entropy while the interaction between hexagonally ordered molecules becomes important. As described for block copolymers this interaction arises from the inhomogeneous side-chain end distribution. In the case of hairy-rodlike polymers it approximately equals to $[53,61,62,64]$

$$
F_{\text {lattice }} \approx-k_{B} T V \frac{\nu}{\nu_{0} l_{K}^{2} l_{u}},
$$

where $\nu$ is the volume and $l_{K}$ the Kuhn length of one chain segment, $l_{u}$ the distance between two consecutive grafting points (the length of the repeat unit), and $v_{0}$ the volume of one repeat unit of the hairy rod. Considering Eq. (2) we obtain the free energy of the hexagonal phase as

$$
F_{H} \approx k_{B} T V c \ln \frac{4 \pi}{\Omega_{H}}-k_{B} T V \frac{\nu}{\nu_{0} l_{K}^{2} l_{u}} .
$$

Due to incompressibility, the concentration $c=1 /\left(\nu_{0} M\right)$ for the melt is directly related to $M$.

Equations (1) and (3) imply that the higher the $M$, the more favorable the hexagonal packing is expected to be. The value of $M$ separating nematic and hexagonal phases for given parameters, $M^{*}$, is estimated from the comparison of the two free energies and reads as

$$
M^{*} \approx \frac{l_{K}^{2} l_{u}}{\nu} \ln \frac{e \Omega_{N}\left(T, M^{*}\right)}{f \Omega_{H}\left(T, M^{*}\right)} .
$$

In the previous publication [53] we assumed both phases to be "equally aligned"-i.e. $\Omega_{N}=\Omega_{H}$-and thus $M^{*}$ independent of the temperature so that

$$
M^{*} \approx \frac{l_{K}^{2} l_{u}}{\nu} \ln \frac{e}{f} .
$$

Finally, we want to express $M^{*}$ in terms of experimental molecular weight and multiply Eq. (5) by the molecular weight of the repeat unit, $M_{u}$, which implies

$$
M_{n}^{*} \approx M_{u} \frac{l_{K}^{2} l_{u}}{\nu} \ln \frac{e \Omega_{N}}{f \Omega_{H}} .
$$

The formula (4) gives us a qualitative understanding about the influence of the systems parameters on the 
nematic-hexagonal transition, while Eq. (6) gives a numerical value for experimental use.

All the details of the molecular alignment have been omitted in the above picture. Instead, we assumed a quite high degree of the orientational ordering, $\Omega$, in both phases. The $\Omega$ and the order parameter $s$ can be derived from a more detailed analysis (for a very fruitful approach to the hairy-rod system see the references of Ballauff [8-10]). However, some of its generic features, such as the temperature and the $M_{n}$ dependence, can be estimated by a phenomenological consideration.

Let us describe the hairy-rod molecule as a chain consisting of stiff segments of length $l_{K}^{H R}$ each, where $l_{K}^{H R}$ is the Kuhn length of the hairy rod (the superscript $H R$ stands for "hairy rod"). In the highly aligned phase at low temperature each segment can fluctuate in the solid angle $\Omega_{0}[2,3]$

$$
\Omega_{0} \approx \frac{d}{l_{K}^{H R}},
$$

where $d$ is the diameter of the backbone. If $T$ is increased, $\Omega_{0}$ increases, too, and can be expressed as

$$
\Omega_{0} \approx \frac{d}{l_{K}^{H R}}(1+C t),
$$

where $C$ is some phenomenological constant which may be different for different aligned phases and where $t=T-T_{g}$ is the temperature measured from $T_{g}$. When the Kuhn segments are assumed to align independently, the total orientational configurational space accessible for the chain is

$$
\Omega_{i}(t) \approx\left(\frac{d}{l_{K}^{H R}}\left(1+C_{i} t\right)\right)^{M l_{u} / l_{K}^{H R}},
$$

where $i=N, H$ refers to nematic or hexagonal, respectively. Hence,

$$
\frac{\Omega_{N}(t)}{\Omega_{H}(t)} \approx\left(\frac{1+C_{N} t}{1+C_{H} t}\right)^{M l_{u} / l_{K}^{H R}} .
$$

Finally, Eqs. (6) and (10) give us the equation for $T$ versus molecular weight binodal linearized upon $t$ as

$$
t \approx A\left(1-\frac{M_{n 0}^{*}}{M_{n}^{*}}\right)
$$

where

$$
M_{n 0}^{*} \approx M_{u} \frac{l_{K}^{2} l_{u}}{\nu} \ln \frac{e}{f},
$$

(i.e., the $M_{n}$ at which a hexagonal-nematic transition occurs at low temperatures) and where

$$
A=\frac{\ln (e / f) l_{K}^{H R} M_{n 0}^{*}}{\left(C_{N}-C_{H}\right) l_{u}} .
$$

The constant $A$ incorporates all the phenomenological constants and is the only adjustable parameter which can be estimated form the experimental data as shown in Sec. IV B.

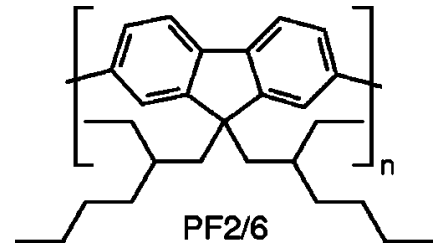

FIG. 3. The chemical structure of poly[9,9-bis(2-ethylhexyl)fluorene-2,7-diyl] (PF2/6).

For more accurate phenomenological analysis allowing for an estimation of $\Omega$ 's, see our parallel study of aligned PF2/6 films [60].

\section{EXPERIMENT}

The preparation of PF2/6 [24,36] (Fig. 3) has been described in detail elsewhere. Six different $M_{n}$ 's were used and determined using GPC (Table I). The samples are denoted henceforth as $\left(M_{n} / M_{w}\right) 10^{-3}-\mathrm{PF} 2 / 6$. The end capping can be used to control the $M_{n}$ [37]. The third sample type had a $\mathrm{N}$-di(4-methyl-phenyl)aminophenyl end cap while the former two first were phenyl end capped. For SANS measurement, PF2/6 was dissolved in deuterated toluene (octadeuterobenzene) $\left(C_{7} D_{8}\right)$ (the degree of deuteration $\left.>99.5 \%\right)$ or carbon tetrachloride $\left(\mathrm{CCl}_{4}\right)$. Both were supplied by Aldrich. For XRD and thermal measurements they were used as such. To produce fibers for fiber XRD a small piece of PF2/6 was annealed at $190{ }^{\circ} \mathrm{C}$ for 5 min and then quickly drawn into a fiber of $5 \mathrm{~mm}$ length and $0.5 \mathrm{~mm}$ diameter in approximately $5 \mathrm{sec}$. The fibers were measured at $130{ }^{\circ} \mathrm{C}, 100^{\circ} \mathrm{C}$, and room temperature. Both the bulk polymer and all samples were stored under nitrogen or helium and/or in dark or under yellow light to prevent any photo-oxidation prior to and during measurements (except SANS measurement where freshly prepared solutions were employed).

The SANS measurements were performed with the smallangle scattering diffractometer "Yellow Submarine" operating on the cold neutron beamline at the Budapest Research Reactor (Hungary) [65]. A broad $q$ range of $0.008-0.3 \AA^{-1}$ was covered using two sample-detector distances; acquisition times of several hours were used for each sample at each detector position. The measurements were done at a temperature of $25{ }^{\circ} \mathrm{C}$. The scattered neutrons were detected by a two-dimensional (2D) position-sensitive detector with pixel

TABLE I. Molecular characteristics of the PF2/6 samples. $M_{w}$ $=\Sigma_{i} W_{i} M_{i} / \Sigma_{i} W_{i}$ where $W_{i}$ is the total weight of the $i$ th polymer species.

\begin{tabular}{ccc}
\hline \hline Material & $M_{n}(\mathrm{~g} / \mathrm{mol})$ & $M_{w}(\mathrm{~g} / \mathrm{mol})$ \\
\hline 3/5-PF2/6 & 2900 & 4800 \\
8/15-PF2/6 & 7600 & 15000 \\
29/68-PF2/6 & 29000 & 68000 \\
$62 / 138-\mathrm{PF} 2 / 6$ & 62000 & 138000 \\
$92 / 190-\mathrm{PF} 2 / 6$ & 91500 & 190000 \\
$147 / 260-\mathrm{PF} 2 / 6$ & $\sim 147000$ & $\sim 262000$ \\
\hline \hline
\end{tabular}




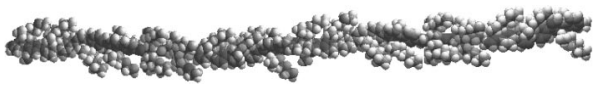

FIG. 4. Molecular model of the local structure of a single 5/2-helical PF2/6 (c=41.6 ̊). Adapted from Ref. [53].

size $1 \times 1 \mathrm{~cm}^{2}$ and the raw data were azimuthally averaged and grouped to about 30 points equidistant in the magnitude of $q$. The scattering curves were corrected for the detector sensitivity, the room background, the scattering of the empty cell, and the transmission of the sample and then converted to the absolute intensity scale using the scattering from a 1-mm-thick water sample. The scattering from deuterated toluene was subtracted as a background. The small incoherent scattering due to the protonated polymer could be disregarded. The $q$ values were calibrated using the Bragg peaks of silver behenate [66].

For comparison, a model of 20 monomer units long $\mathrm{PF} 2 / 6$ with rigid 5/2-helix conformation was used. This corresponds to PF2/ 6 chains of 20 units whose single-molecular geometry was previously calculated using molecular mechanics in vacuo [53] (Fig. 4). No symmetry constraints were applied. Scattering from the atomic model of PF2/6 was calculated from spherical harmonic expansion of the scattering amplitude with the largest order of spherical harmonics being $L_{\max }=15$. The change in scattering contrast caused by the deuterated toluene solvent was taken into account in the scattering length of the nuclei by subtracting the product of the average scattering length density of the solvent $\left(0.56591 \mathrm{fm} / \AA^{3}\right)$ and the solvent volume displaced by the atom in question $\left(V_{\mathrm{C}}=16.44 \AA^{3}, V_{\mathrm{H}}=5.15 \AA^{3}\right)$ [67] from the scattering length of the nucleon $\left(b_{\mathrm{C}}=6.6460 \mathrm{fm}, b_{\mathrm{H}}=\right.$ $-3.7390 \mathrm{fm})$. The data were taken from a Special Feature of Neutron News [68].

The TGA and DSC measurements were performed using a Perkin-Elmer Pyris 1 TGA with a typical precision of $\pm 0.001 \mathrm{mg}$ and a Perkin-Elmer Pyris 1 DSC, respectively. For DSC the samples were first annealed at $180{ }^{\circ} \mathrm{C}$ for $10 \mathrm{~min}$. For both techniques dry samples of $1-8 \mathrm{mg}$ and a sweep rate $10{ }^{\circ} \mathrm{C} / \mathrm{min}$ were used.

Optical micrographs were taken using a Olympus BX51 microscope equipped with crossed polarizers and a Linkam TMS94 hot stage.

Powder and fiber XRD measurements were conducted with a sealed $\mathrm{Cu} K_{\alpha}$ tube using the point focus. The beam was monochromatized with a nickel filter and a totally reflecting glass plate. The beam size was reduced with slits to be $0.1 \mathrm{~mm} \times 0.5 \mathrm{~mm}$ on the sample. The scattering distance was $170 \mathrm{~mm}$ and the intensity was measured with a Hi-Star area detector. To obtain a larger $q$ region an image plate (Molecular Dynamics) was used to detect the fiber XRD data (Figs. 7 and 15, and 16). The $q$ scale was calibrated using a silver behenate standard [66]. Samples were annealed in situ using a Linkam TMS94 hot stage under nitrogen atmosphere. The coherence length $L$ was estimated using the Scherrer formula $L \cong \lambda /(\Delta 2 \theta \cos \theta)$, where $2 \theta$ is the scattering angle, assuming the instrumental function negligible.

\section{RESULTS AND DISCUSSION}

\section{A. Self-organized structure as a function of molecular weight}

The structure of PF2/6 has been studied in the solid state using powder [32] and fiber XRD [43] as well as in in-plane [28] and in axially aligned thin films [52-54] using grazingincidence XRD (GIXD). There are also ellipsometric studies on the optical constants of in-plane [69] and uniaxially aligned PF2/6 films [55]. Besides PF2/6 the structure of PF8 has been studied in fibers $[34,70]$ and in films [28] and its chain conformation related photophysics is known in detail [71].

PF2/6 has been shown to have rigid 5/2-helical molecular structure forming hexagonal self-organized structure in fibers by Lieser et al. [43]. Our later modeling and XRD results support that [52-54] but recently some deviations from the hexagonal cell have been found in bulk and the unit cell has been suggested to be marginally monoclinic with $\gamma$ $=120.4^{\circ}$ by Tanto et al. [32]. More recently, we have qualitatively observed a nematic phase on decreasing $M_{n}[53,54]$. We note first that the qualitative observation of nematic and hexagonal phases [53] of hairy-rod polymer is in agreement with the theory presented in Sec. II.

As a prerequisite of the theory the characteristics of solution formation on the nanometer scale in semidilute solution $(0.1-11 \mathrm{mg} / \mathrm{ml})$ were first probed using SANS, which is used in general for studies of shape and conformations of hairy-rod-like $\pi$-conjugated polymers in the nanometer scale-i.e., the dimensions which are dealt with in Sec. II. For example, substituted PPP was studied by Zaroslov et al. [72], ladder PPP by Hickl et al. [73], and PPV derivatives by Wang et al. [74]. SANS studies of PF's are rather scarce but the exception is a SANS study of dilute PF2/6 solution by Fytas et al. [59]. These authors found that PF2/6 $\left(M_{n}\right.$ $=55 \mathrm{~kg} / \mathrm{mol})$ is rigid in semidilute solution $(0.95-1.7$ $\mathrm{mg} / \mathrm{ml}$ ) where the characteristic distances are of the order of $30 \mathrm{~nm}$ or less and found the persistence length to be around $7 \mathrm{~nm}$ and cross-sectional diameter of the chain $1.8 \mathrm{~nm}$.

In Fig. 5(a) SANS data of semidilute 92/190-PF2/6 solutions are displayed in a log-log representation. The scattering curves show a characteristic -1 decay, indicating that $\mathrm{PF} 2 / 6$ is mostly stiff in the size range of the observation window, at distances roughly from $2 \mathrm{~nm}$ to $60 \mathrm{~nm}$. Deviations from the linear shape of the curves are still visible, indicating some deviations from the stiff behavior. This is better seen in the Kratky plot, Fig. 5(b). Here, the scattering curve of the $9-\mathrm{mg} / \mathrm{ml}$ sample is shown together with the model curve calculated using an all-atom model of the molecule placed in a homogeneous solvent. The deviation from the linear behavior is attributed to local bending. Our previous publication [53] displays a 5/2-helical wormlike model of 20 repeat units in vacuo (Fig. 4). In Fig. 5(b) it is seen that the SANS intensity calculated using atomic coordinates of 20 repeat units of that model fits sufficiently well the experimental data. As the nominal length of $92 / 190-\mathrm{PF} 2 / 6$ is of the order of $200 \mathrm{~nm}$, we see a nonrigid, not a finite size polymer molecule. However, we assume that the chain is locally rigid and $L \gg d$. On the other hand, it may be assumed that the oligomers are rigid small $M_{n}$ LC's after which the 

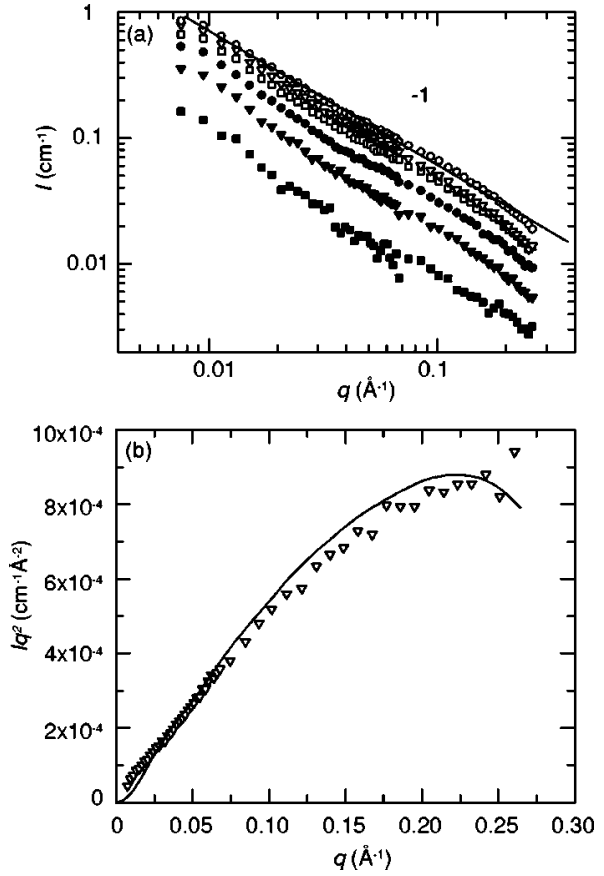

FIG. 5. (a) SANS data of 92/190-PF2/6 in deuterated toluene: $1 \mathrm{mg} / \mathrm{ml}$ (solid squares), $3 \mathrm{mg} / \mathrm{ml}$ (solid down triangles), $5 \mathrm{mg} / \mathrm{ml}$ (solid spheres), $7 \mathrm{mg} / \mathrm{ml}$ (open squares), $9 \mathrm{mg} / \mathrm{ml}$ (open down triangles), and $11 \mathrm{mg} / \mathrm{ml}$ (open spheres). Solid line is the linear fit for the $11 \mathrm{mg} / \mathrm{ml}$ sample having slope -1 . (b) Kratky plot for the $9 \mathrm{mg} / \mathrm{ml} \mathrm{sample}$. Solid curved line is the model scattering of PF2/6 in deuterated toluene (see text). Note that the model curve is not smeared by the finite experimental resolution.

flexibility starts to dominate, a fact which is indeed seen in the relation of orientational order parameter and $M_{n}$ in our parallel paper [60]. Interestingly, the result shown in Fig. 5(a) also suggests that alkyl-substituted PF2/6 can be dissolved in an appropriate solvent up to quite high $(11 \mathrm{mg} / \mathrm{ml})$ concentrations so that its structure is barely altered. The experimental scattering curves of the polymers dissolved in deuterated toluene and $\mathrm{CCl}_{4}$ were essentially similar, indicating no solvent effect and presumably no sign of interaction between the individual polymer chains.

As a semiquantitative theoretical framework we may next estimate the numerical values of the parameters in Eq. (12) for PF2/ 6 for the suggested nematic-hexagonal transition as a function of $M_{n}$. The length of the repeat unit is known from the XRD [52], $l_{u} \approx 8 \AA$ [4]. The backbone fraction can be estimated from $M_{n}$ of the backbone of one repeat unit, $M_{n 0}^{b b}$, and is given by $f \approx M_{n 0}^{b b} / M_{n 0}=162 / 388 \approx 0.4$. To estimate $\nu$ we then calculate the total volume occupied by the side chains in one repeat unit, $\nu_{s c}=(1-f) \nu_{0}=(1-f) \pi R^{2} l_{u}$, where $R$ is the radius of cylindrical polymer known from XRD to be as $R \approx a / 2 \approx 8.3 \AA$. Thus $\nu_{s c} \approx 1040 \AA^{3}$. Correspondingly, the volume per monomer is $\nu \approx \nu_{s c}$ (number of $\mathrm{C}$ atoms) $=1040 \AA^{3} / 16 \approx 65 \AA^{3}$. The Kuhn segment length may be estimated to be that of aliphatic chain, for which $l_{K} \approx 10 \AA$ [3]. Then, Eq. (12) yields for PF2/6 the transition value $M_{n}^{*}$ $\approx 10^{4} \mathrm{~g} / \mathrm{mol}$.

The samples for which $M_{n}>M_{n}^{*}$ are henceforth denoted as "high molecular weight" (HMW) and those for which

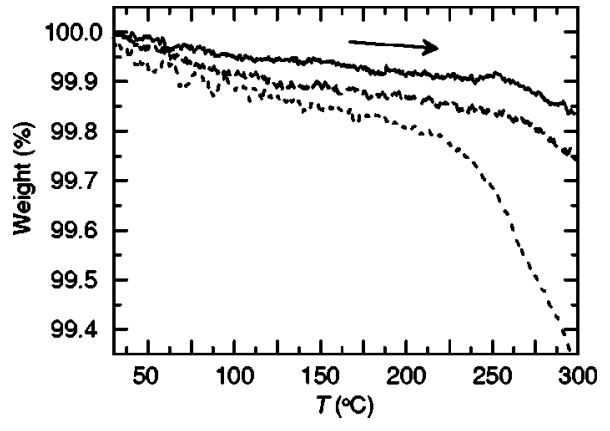

FIG. 6. TGA curves of 92/190-PF2/6 (solid line), 29/62 -PF2/6 (dashed line), and 3/5-PF2/6 (dotted line) indicating excellent thermal stability up to $300{ }^{\circ} \mathrm{C}$. The samples were heated at the rate $10{ }^{\circ} \mathrm{C} / \mathrm{min}$.

$M_{n}<M_{n}^{*}$ as "low molecular weight" (LMW) materials. $M_{n}^{*}$ is the threshold value for the nematic-hexagonal transition which should be experimentally observed. First we note that the numerical value of $M_{n}^{*}$ is between the values of the polymers $\left(M_{n}=7.6\right.$ and $\left.150 \mathrm{~kg} / \mathrm{mol}\right)$ employed in our previous, qualitative work [53]. We point out that this paper deals with the bulk phase without concerning the surface effects but the length of the repeat unit and the diameter of PF2/6 can be accurately measured in both bulk $[32,43,53]$ and thin films $[28,52-54]$, and the values are slightly altered. In both cases, we get practically the same $M_{n}^{*}$ and thus in the parallel publication [60] we may rely on the present result when considering the aligned thin PF2/6 films.

As an experimental prerequisite all polymers studied were also analyzed using TGA by heating them to $300{ }^{\circ} \mathrm{C}$ under nitrogen. Figure 6 presents a selection of TGA curves. The mass of all the samples remains essentially constant up to $250{ }^{\circ} \mathrm{C}$ and some minor changes may occur after that. The weight loss increases slightly on decreasing $M_{n}$ after $200{ }^{\circ} \mathrm{C}$. As the largest measured weight loss $(3 / 5-\mathrm{PF} 2 / 6)$ at $300{ }^{\circ} \mathrm{C}$ was as low as $0.5 \%$, we conclude the explored PF2/6 to be thermally stable over the studied conditions. Because of the photo-oxidation of single repeat units (see Hintschich et al. [75]), PF's may show keto defects which are seen as a broad yellow PL. It is noteworthy that this yellow PL band is seen already in very low fluorenone content $(\sim 0.1 \%$ of repeat units [75]). The samples used have a lower concentration of keto defects than this, and it is expected that they have no effect on general phase behavior. To sum up we assume that $\mathrm{PF} 2 / 6$ does not suffer from thermal degradation under inert gas and so far we do not observe characteristic yellow PL the studied materials may not be oxidized either.

In order to study the self-assembled structure, all the samples were then studied using powder XRD measurements and the results obtained turned out to be in surprisingly good agreement with the theoretical prediction. All HMW samples $\left(M_{n} \geqslant 29 \mathrm{~kg} / \mathrm{mol}\right)$ have crystalline hexagonal and LC nematic structure at lower and higher temperatures, respectively, shown, for example, in Fig. 7. The XRD curves have clear 101 and 005 reflections, corresponding to the fivefold helical structure, proposed by Lieser et al. [43]. It is noteworthy that the annealing cycles substantially increase the crystallite size, as also observed by Tanto et al. [32]. 


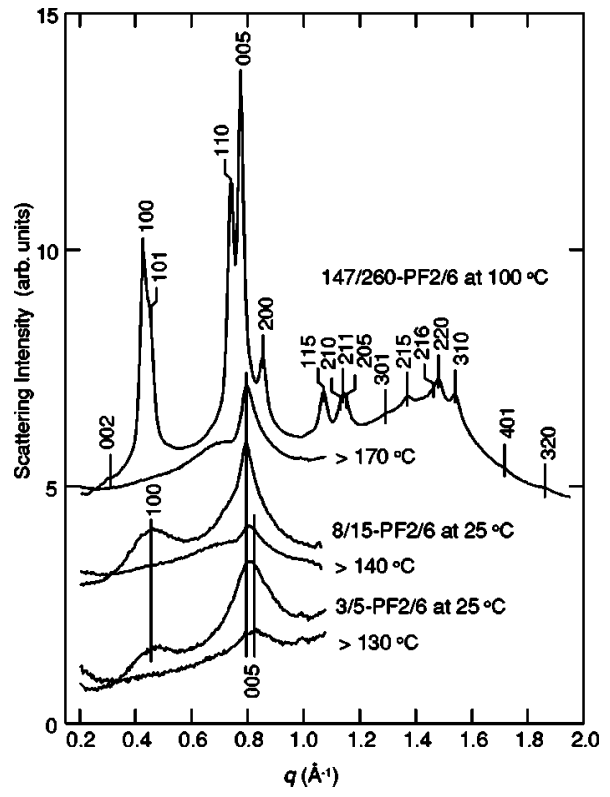

FIG. 7. Powder XRD pattern of 147/260-PF2/6, 8/15-PF2/6, and $3 / 5-\mathrm{PF} 2 / 6$ at various temperatures. A total of 15 reflections of $147 / 260-\mathrm{PF} 2 / 6$ are discernible and assigned to a hexagonal unit cell with $a=16.99 \AA, c=40.55 \AA$, and $\gamma=120^{\circ}$. The sample was annealed for $2 \mathrm{~h}$ at $180{ }^{\circ} \mathrm{C}$ and cooled at $3{ }^{\circ} \mathrm{C} / \mathrm{min}$. 8/15-PF2/6 and 3/5-PF2/6 show nematic characteristics with $c=30.5 \AA$. These samples were annealed at $180{ }^{\circ} \mathrm{C}$ and $130{ }^{\circ} \mathrm{C}$, respectively.

The LMW samples in Fig. 7, on the other hand, do not form a well-ordered hexagonal crystal. They show only one relatively sharp reflection which is identified as 005 , whereas those related to hexagonal packing (i.e., 100 and 110) appear as broad humps. Thus by decreasing $M_{n}$ below the $M_{n}^{*}$ limit for $T \leqslant T_{g}$ we indeed pass the predicted structural nematichexagonal transition and the PF2/6 hairy rods are nematic rather than hexagonal, as illustrated in Fig. 2. We note that 8/15-PF2/6 may show traces of hexagonal peaks (see discussion below) but the qualitative difference to HMW materials is significant. The coherence lengths of nematic samples are about $40 \AA$ in the hexagonal direction and of the order of the chain length in the c direction. We assume that LMW samples are still five-helical on the basis of similarities between unit cell dimensions $(a=15.9-16.0 \AA, \quad c$ $=38.5-39.5 \AA$ ). As a helical molecular structure is an indirect phenomenological indication of stiffness, this supports the presumption that LMW samples are rigid and $L \gg d$. Hence, Eq. (1) is assumed to be meaningful. We stress that the chains are still densely packed three per unit cell, actually even more densely $\left(73.4 \AA^{2} /\right.$ chain) than in the HMW samples $\left(78.9 \AA^{2} /\right.$ chain). The nematic state obtained by heating the HMW sample above hexagonal-nematic transition differs from that of LMW sample. In such case we can only see a packing of individual chains and the structure seems much less dense (ca. $95 \AA^{2} /$ chain).

\section{B. Phase behavior as a function of molecular weight}

In order to get an idea of phase transitions, all the polymers were studied using DSC by annealing them at $180{ }^{\circ} \mathrm{C}$

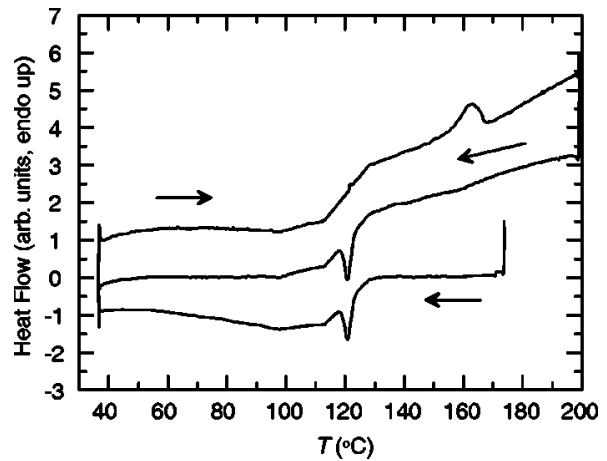

FIG. 8. DSC-cycle of hexagonal 147/260-PF2/6. The linear base-line corrected curve reveals the ill-defined kink at somewhat above $80{ }^{\circ} \mathrm{C}$ potentially representing a glass transition (cf. Nothofer [75]). Data show an order-order transition at $155-167^{\circ} \mathrm{C}$ and $118-122{ }^{\circ} \mathrm{C}$ upon heating and cooling, respectively.

and then by cooling them down to room temperature and by heating them again back to $180{ }^{\circ} \mathrm{C}$. PF2/6 was previously studied using DSC by Nothofer [76] (see also Ref. [24]) and Grell et al. [36]. Nothofer used PF2/6 with $M_{n}$ $=122 \mathrm{~kg} / \mathrm{mol}$ and reported maxima at $165^{\circ} \mathrm{C}$ during heating and $132{ }^{\circ} \mathrm{C}$ during cooling. In his study, the heating curve started to rise at $155^{\circ} \mathrm{C}$. Correspondingly, Tanto et al. [32] observed $T_{g}$ at $80^{\circ} \mathrm{C}$ and the first-order transition at $165^{\circ} \mathrm{C}$ during heating and at $132{ }^{\circ} \mathrm{C}$ during cooling. $T_{g}=80^{\circ} \mathrm{C}$ was originally estimated using the slight difference in the slope of the curve by Nothofer [76]. We note that the hysteresis in annealing cycles and the difficulty in determining $T_{g}$ are characteristic of PF's.: Banach et al. [51] saw large hysteresis in their DSC curve of F8BT. Papadopoulos et al. [50] who studied PF8 and corresponding oligomers reported in turn that $T_{g}$ is obvious for oligomers but nearly impossible to determine for polymer using DSC alone.

Figure 8 shows a DSC trace of $147 / 260-\mathrm{PF} 2 / 6$ in our study. When the linear base line has been subtracted from the curve in Fig. 8 it reveals an ill-defined kink at somewhat above $80{ }^{\circ} \mathrm{C}$, which may be assumed to represent a glass transition. However, we cannot rigorously establish that fact but the kink of the heating cycle at $110-130{ }^{\circ} \mathrm{C}$ for $147 / 260$ PF2/6 may also be due to a partial recrystallization at $T$ $>T_{g}$. Instead, we note that the curve shows peaks at higher $T$ with considerable hysteresis qualitatively corresponding the previous results $[36,76]$. A sharp endothermic peak during heating at $165^{\circ} \mathrm{C}$ and corresponding distinctive exothermic peak during cooling at $122{ }^{\circ} \mathrm{C}$ associated with the heat $9.4 \mathrm{~J} / \mathrm{g}$ and $-3.5 \mathrm{~J} / \mathrm{g}$, respectively, are recognized to represent the nematic-hexagonal transition.

Figure 9 presents the DSC curve of 3/5-PF2/6 and 8/15PF2/6. Unlike HMW materials, 3/5-PF2/6 does not show any sharp peaks during slow cycles but a practically featureless DSC curve from $180{ }^{\circ} \mathrm{C}$ down to $-177^{\circ} \mathrm{C}$. Upon heating the present data show tiny features at 48 and $71{ }^{\circ} \mathrm{C}$, which we cannot yet identify. $8 / 15-\mathrm{PF} 2 / 6$ reveals usually a curve similar to 3/5-PF2/6 but the curve shown in Fig. 9 shows a tiny peak at approximately $80^{\circ} \mathrm{C}$, which we may interpret either a glass transition or partial recrystallization of highermolecular-weight fractions (see the XRD patterns of Fig. 13 

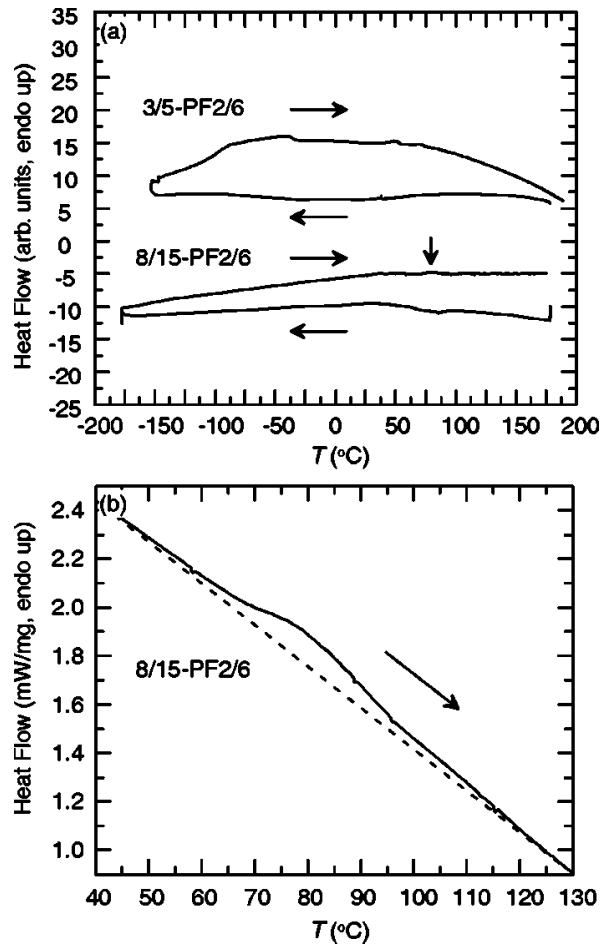

FIG. 9. (a) DSC cycle of nematic 3/5-PF2/6 and 8/15-PF2/6. The linear base-line-corrected curves. See a feature in curve at ca. $80{ }^{\circ} \mathrm{C}$ marked with a vertical arrow. (b) Magnification of the DSC data of $8 / 15-\mathrm{PF} 2 / 6$ on heating (solid line) and the corresponding linear base line (dotted line).

and discussion thereinafter). We conclude that there is a clear qualitative steplike difference between the behavior of LMW and HMW samples. The sharp peaks observed in the data of HMW samples represent transition between the hexagonal and nematic state and consequently we expect that LMW samples show one-dimensional nanometer-scale structure, nematic or glassy nematic phase essentially at any temperature.

The focus of interest is next put on the region where $M_{n}$ decreases down to the predicted hexagonal-nematic transition value $M_{n}^{*}$ for low temperature. Figure 10 shows the DSC curves of three HMW polymers showing prominent peaks at

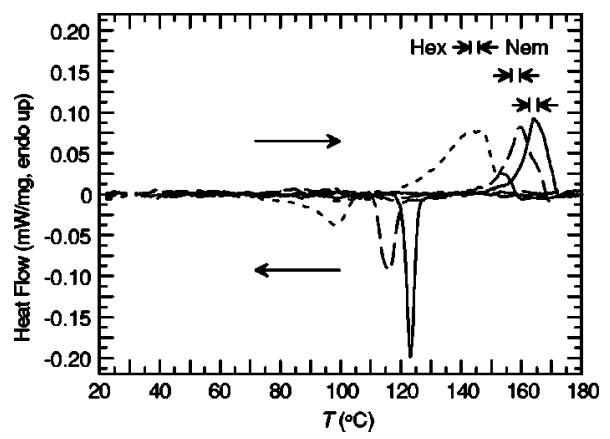

FIG. 10. The DSC curves of hexagonal 92/190-PF2/6 (solid line), 62/138-PF2/6 (dashed line), and 29/68-PF2/6 (dotted line) during heating cooling cycle (at $10{ }^{\circ} \mathrm{C} / \mathrm{min}$ ) indicating the decrease of nematic-hexagonal transition as a function of $M_{n}$. The fitted base line was subtracted from the data.

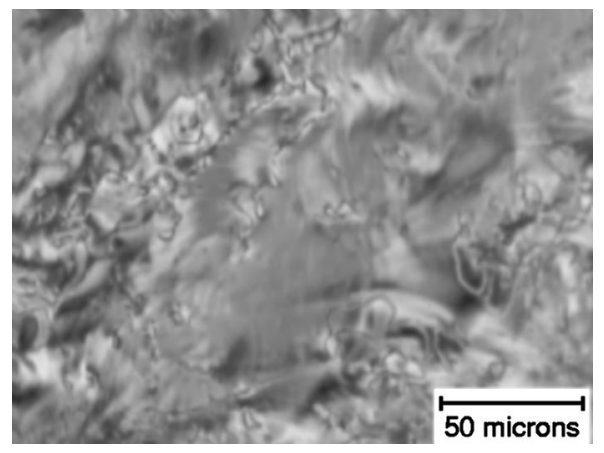

FIG. 11. Optical micrograph of bulk fluid 29/68-PF2/6 between crossed polarizers at $180{ }^{\circ} \mathrm{C}$.

99,116 , and $124^{\circ} \mathrm{C}$ and at 142,156 , and $164^{\circ} \mathrm{C}$ during cooling and heating, respectively. This indicates that the position of the nematic-hexagonal transition is quite constant for $M_{n}>62 \mathrm{~kg} / \mathrm{mol}$ but decreased when decreasing $M_{n}$ below that. Nothofer [76] reported a qualitative drop in the first-order phase transitions for a diverse set of PF's and Papadopoulos et al. [50] reported quantitatively resembling and even a larger drop of the first-order transitions of a wide set of PF8 oligomers and the disappearance of the peak for the lowest oligomers. Their data seem to also indicate slight peak broadening when decreasing the degree of polymerization [50]. We note that PF2/6 (Fig. 10) shows large peak broadening, too, but the reason for that is unclear. It could be assumed that the nematic-hexagonal transition becomes fuzzier with increasing $M_{n}$. The system, which is probably very sluggish-i.e., viscous, etc.-might temporarily stick in some metastable states. However, we note that the opposite happens and the lower $M_{n}$ show broader peaks. As the sample size was rather equal and the heating rate equal, this may not be an experimental error but a real effect. Since PF2/6 is rather polydisperse, it may be asked how this influences the transition. We cannot easily estimate this effect on the peak broadening either, because $M_{w} / M_{n}$ of all the samples was quite similar. After all, we interpret that the DSC results show $T_{g}$ at ca. $80{ }^{\circ} \mathrm{C}$ for all samples of different $M_{n}$ but a distinct lowering of the nematic-hexagonal transition temperature with decreasing $M_{n}$ for HMW PF2/6 samples. These results resemble those of Banach et al. [51] who observed that $T_{g}$ did not shift considerably while the order-order transition shifted $20{ }^{\circ} \mathrm{C}$ for F8BT as $M_{n}$.

While DSC gives us an idea of how $M_{n}$ influences the phase transitions, the phases themselves may be recognized using polarized microscopy and XRD as a function of temperature. The nematic state of 29/68-PF2/6 is illustrated using polarized microscopy in Fig. 11. Although the hairy rods are discussed in the terms of block copolymers, the transition seen in DSC curves is not an order-disorder transition as seen in archetypical diblock copolymers but rather an order-order transition. No isotropic phase is observed above the transition seen in DSC data but a beautiful birefringence is seen in all conditions $\left(<200{ }^{\circ} \mathrm{C}\right)$ of $\mathrm{PF} 2 / 6$.

Figure 12 shows an example of powder XRD patterns of annealed HMW material as a function of temperature upon very slow cooling $\left(0.2{ }^{\circ} \mathrm{C} / \mathrm{min}\right)$. As expected based on the DSC curve (Fig. 8) a hexagonal phase is seen for $T$ 


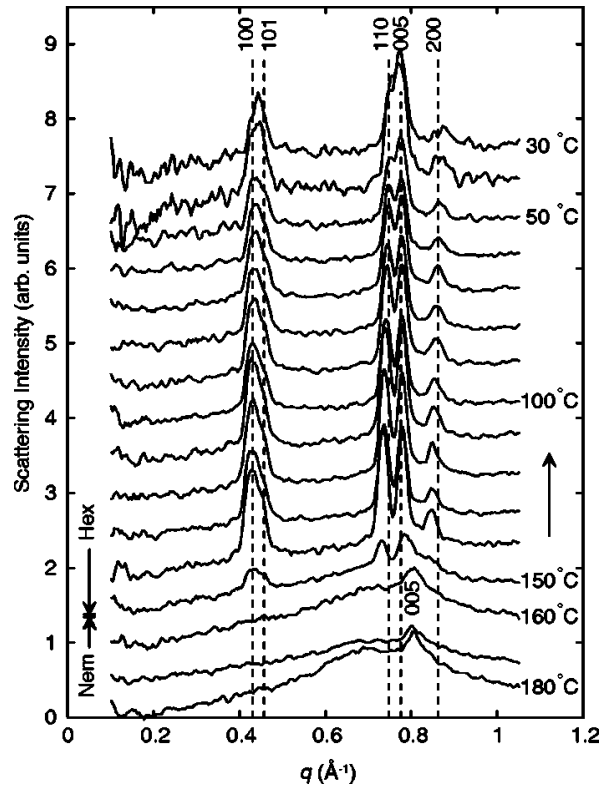

FIG. 12. The powder XRD patterns of $147 / 260-\mathrm{PF} 2 / 6$ as a function of temperature during cooling $\left(0.2^{\circ} \mathrm{C} / \mathrm{min}\right)$ at intervals of $10^{\circ}$. Note how the hexagonal peaks disappear and the position of 005 reflection changes in the hexagonal-nematic transition at $150{ }^{\circ} \mathrm{C}$ (cf. Fig. 7). The lattice parameters are $a=16.82 \AA, c$ $=40.46 \AA$ for hexagonal and $c \sim 39.5 \AA$ for nematic.

$\leqslant 160{ }^{\circ} \mathrm{C}$ and it disappears above that. It is conspicuous that nematic features appear upon the hexagonal-nematic transition and also that the position of the 005 reflection is moved towards a wider scattering angle and the reflection is significantly broadened. Thus, the characteristics of the XRD pattern-i.e., the disappearance of hexagonal peaks and the shape and position of the 005 reflection-of the HMW samples above the hexagonal-nematic transition corresponds qualitatively to those seen in LMW samples (cf. Fig. 7).

Figure 13 shows the XRD patterns of $8 / 15-\mathrm{PF} 2 / 6$, an ex- ample of LMW material, as a function of $T$. Consistently with DSC data, XRD patterns of LMW materials show no distinctive transitions but indicate a nematic or glassy nematic regime at any temperatures studied. We may occasionally see traces of hexagonal structure in the 8/15-PF2/6 sample upon heating [Fig. $13(\mathrm{a})$, at $110-130^{\circ} \mathrm{C}$ ], too, probably due to the recrystallization of higher $M_{n}$ fractions but this effect cannot be reproduced easily. Given the relative strength of the scattering intensities they can also be due to a buried metastable phase. These traces were never seen for 3/5-PF2/6. In simple LC's, polydispersity normally leads to a macro phase separation of the long species which form ordered phase from the short ones in the isotropic phase and thus being the case we should also observe coexistence of XRD features of both phases. As optical microscopy suggests that the PF2/6 is not seriously macro phase separated and because these traces may not be easily reproduced, we find that higher- $M_{n}$ fractions do not critically disturb the comparison between experiment and theory where the monodispersity is assumed (cf. Sec. II). Instead, the higher-weight fractions may contribute to the sharpness of the meridional reflection (cf. Fig. 7). Nonetheless, since there is the large difference between the local order in HMW and LMW and hexagonal and nematic samples together with the studied large region in $M_{n}$ and rather large steps in $M_{n}$ between the samples, this aspect may be neglected.

The hexagonal-nematic transitions obtained from the DSC and XRD measurements are collected in Table II. We underline that for HMW samples the accurate positions of the nematic-hexagonal transition depend much on the heating rate and the method of determination and we estimate the error to be $\pm 5^{\circ} \mathrm{C}$. For instance, for $147 / 260-\mathrm{PF} 2 / 6$ we generally observe the transition at $165 \pm 5{ }^{\circ} \mathrm{C}$ on heating and $150 \pm 5^{\circ} \mathrm{C}$ on cooling (cf. Fig. 12). 92/190-PF2/6 shows an overlap of the transition points between DSC and XRD in heating but the transition determined using XRD upon cooling at $0.2^{\circ} \mathrm{C} / \mathrm{min}$ differs more from that seen upon heating compared to the other samples. So this measurement may
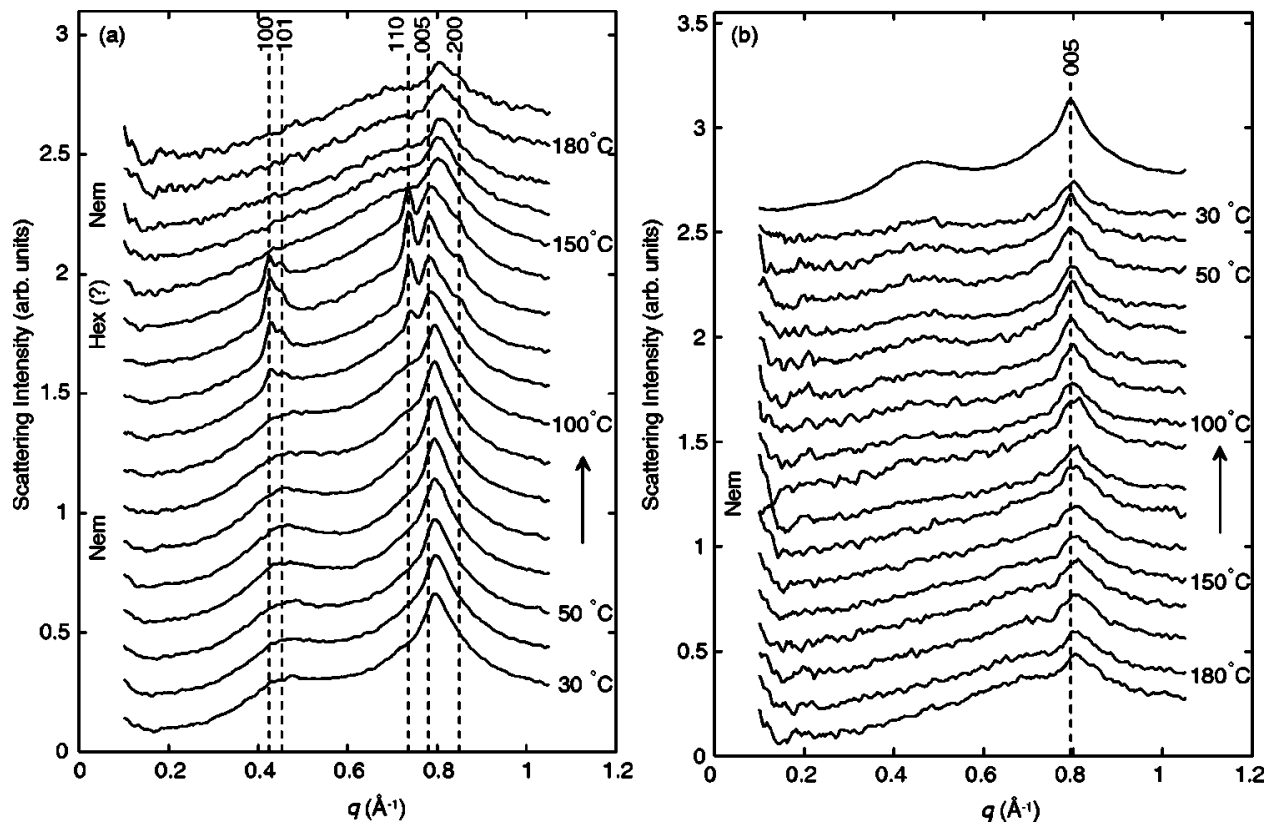

FIG. 13. The powder XRD patterns of $8 / 15-\mathrm{PF} 2 / 6$ as a function of temperature during slow (a) heating and (b) cooling (both $0.2^{\circ} \mathrm{C} / \mathrm{min}$ ) at intervals of $10^{\circ}$. The sample is characteristically nematic with $c=39.51 \AA$ but traces of hexagonal phase may appear between 110 and $130{ }^{\circ} \mathrm{C}$ with $a=17.06 \AA$ and $c=40.18 \AA$. Note that the scan is not reversible on cooling. 
TABLE II. Hexagonal-nematic transitions of the PF2/6 samples determined using DSC and XRD.

\begin{tabular}{|c|c|c|c|c|}
\hline Material & $\begin{array}{c}\text { DSC } \\
\text { heating } \\
10{ }^{\circ} \mathrm{C} / \mathrm{min} \\
\left({ }^{\circ} \mathrm{C}\right)\end{array}$ & $\begin{array}{c}\text { DSC } \\
\text { cooling } \\
10{ }^{\circ} \mathrm{C} / \mathrm{min} \\
\left({ }^{\circ} \mathrm{C}\right)\end{array}$ & $\begin{array}{c}\text { XRD } \\
\text { heating } \\
0.2^{\circ} \mathrm{C} / \mathrm{min} \\
\left({ }^{\circ} \mathrm{C}\right)\end{array}$ & $\begin{array}{c}\mathrm{XRD} \\
\text { cooling } \\
0.2{ }^{\circ} \mathrm{C} / \mathrm{min} \\
\left({ }^{\circ} \mathrm{C}\right)\end{array}$ \\
\hline 3/5-PF2/6 & & & Nem & Nem \\
\hline $8 / 15-\mathrm{PF} 2 / 6$ & & & Nem & Nem \\
\hline $\begin{array}{l}29 / 68- \\
P F 2 / 6\end{array}$ & $142 \pm 5$ & $99 \pm 5$ & $155 \pm 5$ & $134 \pm 5$ \\
\hline $\begin{array}{c}62 / 138- \\
\text { PF2/6 }\end{array}$ & $156 \pm 5$ & $116 \pm 5$ & $163 \pm 5$ & $150 \pm 5$ \\
\hline $\begin{array}{c}92 / 190- \\
\text { PF2/6 }\end{array}$ & $164 \pm 5$ & $124 \pm 5$ & $164 \pm 5$ & $145 \pm 5$ \\
\hline $\begin{array}{c}\text { 147/260- } \\
\text { PF2/6 }\end{array}$ & $165 \pm 5$ & $122 \pm 5$ & $163 \pm 5$ & $149 \pm 5$ \\
\hline
\end{tabular}

contain a larger experimental error that we cannot yet address.

Next, there is a need to give the theoretical counterpart to the Table II. Equation (11) gives an approximate expression for the hexagonal and nematic phase coexistence line above $T_{g}$. In the limit $T^{*} \sim T_{g}$ it predicts the $M_{n}$ at a transition equal to $M_{n}^{*}$ corresponding to Eq. (6). Next, the correct limit in the case $M_{n} \gg M_{n 0}^{*}$ can be assured by a corresponding choice of the constant $A$ of Eq. (13), which can be extracted from the experiment. Finally, the binodal, Eq. (11), can be seen as a phenomenological interpolation between these limiting cases. As follows from Eq. (11) the hexagonal-nematic transition temperature for very high $M_{n}$ molecules is $T\left(M_{n}^{*}\right.$ $\left.\gg M_{n o}^{*}\right)=T_{g}+A$. As we note that the transition temperature seems to saturate for the higher $M_{n}(\geqslant 62 \mathrm{~kg} / \mathrm{mol})$ we take the maximum of the hexagonal-nematic transition of 147/ 260-PF2/6 based on DSC and XRD $\left(\sim 170^{\circ} \mathrm{C}\right)$ (Table II) as well as the $T_{g}$ determined by Nothofer [76] and seen in Fig. $9\left(80{ }^{\circ} \mathrm{C}\right)$. Thus, $A \approx(170-80){ }^{\circ} \mathrm{C}=90{ }^{\circ} \mathrm{C}$.

Figure 14 sums up the primary result of this paper: The theoretical phase diagram of PF2/6 as a function of $M_{n}$ [Eq. (11)] and the compilation of the experimental results presented in Table II: For lower $M_{n}$ 's only the nematic phase is possible above $T_{g}$. At lower $T$ the nematic-hexagonal transition as a function of $M_{n}$ is seen and hexagonal-nematic transition upon heating is observed for the HMW phase and this transition depends weakly on $M_{n}$. Despite the simplicity of the theoretical considerations, the results are indeed in surprisingly good agreement with the DSC scans upon heating and the XRD results in spite of the fact that the experiment does not concern monodisperse materials (cf. Table I) while the theory does.

\section{Overall alignment}

The phase diagram (Fig. 14) forms the quantitative starting point when studying thermotropic orientation in PF2/6 films in our parallel report [60]. The importance of the phase diagram of PF2/6 is that in order to form uniaxially well-

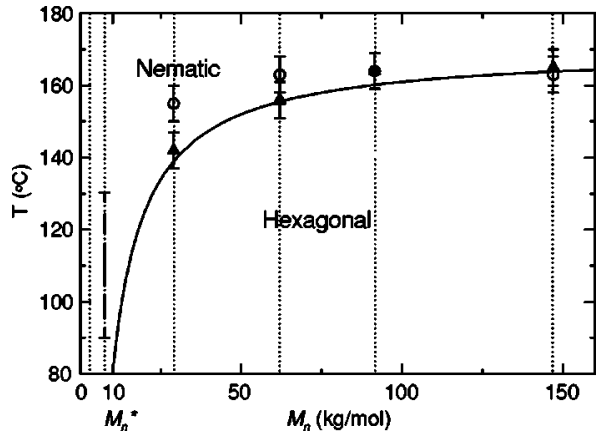

FIG. 14. Theoretical phase diagram of $\mathrm{PF} 2 / 6$ as a function of $M_{n}$ for $T \geqslant T_{g}$ and the compilation of the corresponding experimental results. The solid line shows the theoretical nematic-hexagonal phase transition, Eq. (11). The hexagonal-nematic transitions of annealed samples based on DSC and XRD measurements upon heating at $10{ }^{\circ} \mathrm{C} / \mathrm{min}$ and $0.2{ }^{\circ} \mathrm{C} / \mathrm{min}$ are marked by solid triangles and open circles, respectively. The grid lines correspond to the $M_{n}$ of experimentally studied materials in this work. The vertical bar at 90-130 ${ }^{\circ} \mathrm{C}$ for $M_{n}=8 \mathrm{~kg} / \mathrm{mol}$ shows the approximate position of occasionally seen hexagonal traces.

aligned structures, PF2/6 must be heated up to the nematic regime whose position can be directly read in Fig. 14 for each $M_{n}$. Besides high local order, such as a LC, PF2/6 is particularly well suited to achieve a high degree of overall alignment and it is reported to align better in films than PF8 [24].

While the aligned fibers are a good framework for the aligned thin films they naturally make detailed fiber XRD studies and structural considerations possible, too. There are detailed fiber XRD studies of PF8 [34,70] and PF2/6 [43], and 147/260-PF2/6 has been shown to form well-aligned fibers [43]. All our samples align well in fibers, which allow careful indexation of HMW hexagonal materials. Figures 15 and 16 present fiber XRD patterns of 92/190-PF2/6 at $130{ }^{\circ} \mathrm{C}$ and at room temperature, respectively, while Table III displays the reflections shown in Fig. 16. The following general notes can be made. First, as shown in Fig. 15 the aligned state is well present above the $T_{g}$. Second, the char-

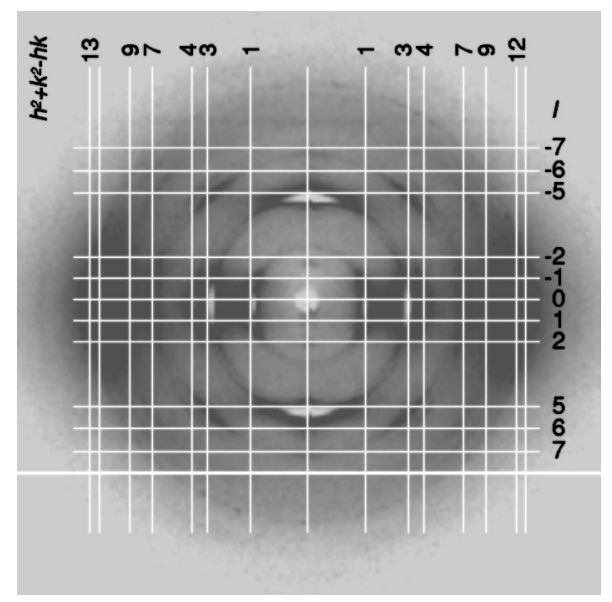

FIG. 15. Two-dimensional fiber XRD patterns of 92/190 $-\mathrm{PF} 2 / 6$ at $130^{\circ}$. 
TABLE III. Primary XRD peaks and their full width at half maxima (FWHM) of 92/190-PF2/6 observed in Fig. 16.

\begin{tabular}{ccc}
\hline \hline$h k l$ & $q\left(\AA^{-1}\right)$ & FWHM $\left(\AA^{-1}\right)$ \\
\hline 100 & 0.4304 & 0.021 \\
110 & 0.7470 & 0.024 \\
200 & 0.8615 & 0.023 \\
$210^{\mathrm{a}}$ & 1.1414 & 0.033 \\
$211^{\mathrm{a}}$ & 1.1519 & 0.060 \\
220 & 1.4942 & 0.032 \\
310 & 1.5594 & 0.032 \\
320 & 1.8819 & 0.038 \\
410 & 1.9773 & 0.039 \\
420 & 2.2769 & 0.050 \\
101 & 0.4532 & 0.046 \\
111 & 0.7660 & 0.035 \\
201 & 0.8706 & 0.037 \\
115 & 1.0763 & 0.038 \\
205 & 1.1570 & 0.040 \\
215 & 1.3786 & 0.053 \\
216 & 1.4685 & 0.049 \\
002 & 0.3010 & 0.031 \\
005 & 0.7790 & 0.027 \\
007 & 1.0776 & 0.037 \\
0010 & 1.5527 & 0.027 \\
0012 & 1.8746 & 0.075 \\
\hline \hline
\end{tabular}

${ }^{\mathrm{a}}$ The peaks 211 overlaps with 210 .

acter of the hexagonal phase is only marginally dependent on the $M_{n}$ and, third, the nematic phase shows consistently smaller $c(39.5 \AA)$ compared to the hexagonal phase $(c$ $=40.4 \AA)$. Both values are less than a value (41.6 $⿱$ ) obtained from our previous molecular mechanics calculated

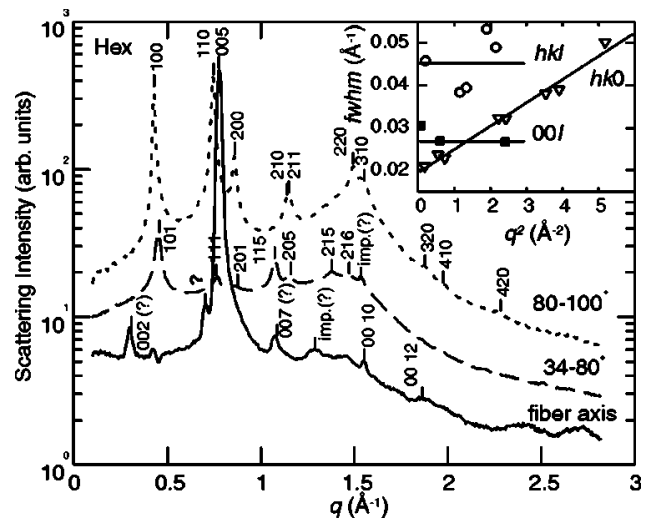

FIG. 16. one-dimensional fiber XRD patterns of 92/190 $-\mathrm{PF} 2 / 6$ at room temperature. Dotted and dashed lines present the integrated cones (with respect to the fiber axis) while the solid line shows the scattering along the fibre axis corresponding to the $\mathbf{c}$ axis. Inset shows full width at half maxima (FWHM) of tilted $\left(34-80^{\circ}\right)$ $h k l$ (open spheres), hexagonal $h k 0$ (open down triangles), and meridional (fiber axis) $00 l$ reflections (solid squares), respectively, as a function of $q^{2}$. The solid lines are corresponding linear fits. model [53] but the more advanced determination of Tanto et al. [32] yields the value $c=40.8 \AA$, which is in agreement with our experimental result.

Besides the reflections which are consistent with the fivehelix there are a few extra reflections that may not be addressed for the five-helix. Some of these may be indexed quite closely to 002, 007, and 0012 (cf. Table III) but these should be forbidden for strict helical symmetry. It should be expected that the side chains do not have fivefold symmetry which would explain these peak. However, the reason why the extra reflections are restricted to these remains partially open. The five-helical PF2/6 does not possess the symmetry which is required for genuine crystalline structure.

The inset of Fig. 16 shows that the peak widths of reflections in different directions behave differently as a function of scattering angle. Those along fiber axis stay sharp, indicating true crystalline order (crystalline size $200 \AA$ ). In the hexagonal direction the order is likened to paracrystalline and the peak broadening scales as $q^{2}$. The limiting coherence length is $300 \AA$, indicating high local lateral order. The local order of PF2/6 compares well to any other LC $\pi$-conjugated covalent, such as PAT's $[6,57]$. The reflections with mixed indices are weak and invariably broader.

\section{CONCLUSIONS}

In conclusion, an investigation has been conducted to clarify the structure formation and phase behavior of PF2/6 as a function of $M_{n}$. PF2/6 was selected because it is both a good choice as a model hairy rod for theory and experiment and simultaneously a useful polymer in applications of molecular electronics and thin-film devices. Using DSC and XRD combined the $M_{n}$-dependent phase diagram of melt PF2/6 has been addressed. It has been compared to that of the free-energy argument of hairy rods. This forms one aspect when optimizing thermotropically aligned PF2/6 films.

First, as a prerequisite of the work, the thermal stability of PF2/6 has been studied using TGA and the stiffness using SANS. The scattering curve was compared to the theoretical model of a single 20-mer embedded in featureless deuterated toluene. PF2/6 has been found to be thermally stable in the studied conditions and reasonably stiff to be phenomenologically understood in the terms of rigid rods at distances of the order of 2-60 nm.

Second, the phase behavior has been discussed based on a free-energy treatment and accounting for the orientation part of the free energies of the nematic and hexagonal phases. As a result of a simple semiquantitative analysis, the nematichexagonal transition has been identified as a function of $M_{n}$ for $T \geqslant T_{g}$ and a theoretical phase diagram has been formed for PF $2 / 6$ with $M_{n}=3-160 \mathrm{~kg} / \mathrm{mol}$ and $T>80{ }^{\circ} \mathrm{C} \sim T_{g}$. At $T<80{ }^{\circ} \mathrm{C}$ the nematic-hexagonal transition as a function of $M_{n}$ is seen at $M_{n}^{*}=10^{4} \mathrm{~g} / \mathrm{mol}$, defining the LMW and HMW regimes. The hexagonal-nematic transition upon heating is observed for the HMW regime. This transition depends weakly on $M_{n}$, being at $140-165^{\circ} \mathrm{C}$ for $M_{n}>M_{n}^{*}$.

Third, the phase behavior and structure formation have been probed using XRD and DSC and supported by polarized microscopy and a detailed experimental phase diagram 
has been formed and discussed. Reasonable agreement with theory has been found.

Fourth, the further details of nematic and hexagonal structures have been explored. The nematic phase of LMW materials has been observed to be denser than the hightemperature nematic phase of HMW compounds. The hexagonal phase has been found to be locally highly ordered, revealing coherence length at least $300 \AA$, and a large number of reflections are resolved in fiber XRD patterns, indicating paracrystalline rather than genuine crystalline equatorial order. We also find that all these materials including decamer reveal the previously found rigid five-helix hairy-rod-like molecular structure of PF2/6.

\section{ACKNOWLEDGMENTS}

This study has been funded by One North East (UK) UIC nanotechnology grant. B.P.L receives financial support from Sony Europe Plc. The SANS experiment was supported by the EC within the framework of Contract No. RII3-CT-2003505925. M.K. thanks the Jenny and Antti Wihuri Foundation and the Academy of Finland for support and Professor M. J. Winokur of the University of Wisconsin-Madison for valuable comments and access to unpublished results as well as Professor H. Sirringhaus of the University of Cambridge and H-G. Nothofer of Sony Europe Plc for discussions. Thanks are also due to W. D. Carswell of the University of Durham for access to the thermal analysis.
[1] P.-G. de Gennes, Scaling Concepts in Polymer Physics (Cornell University Press, Ithaca, 1979).

[2] A. N. Semenov and A. R. Khokhlov, Sov. Phys. Usp. 156, 427 (1988).

[3] A. R. Khokhlov, in Liquid Crystallinity in Polymers, edited by A. Ciferri (VCH, New York, 1991), p. 97.

[4] A. Y. Grosberg and A. R. Khokhlov, Statistical Physics of Macromolecules (AIP, Woodbury, NY, 1994).

[5] P. G. de Gennes and J. Prost, The Physics of Liquid Crystals (Oxford University Press, Oxford, 1998).

[6] M. J. Winokur, in Handbook of Conducting Polymers, edited by T. A. Skotheim, R. L. Elsenbaumer, and J. R. Reynolds (Marcel Dekker, New York, 1998), p. 707.

[7] M. J. Winokur and W. Chunwachirasiri, J. Polym. Sci., Part B: Polym. Phys. 41, 2630 (2003).

[8] M. Ballauff, Macromolecules 19, 1366 (1986).

[9] M. Ballauff, J. Polym. Sci., Part B: Polym. Phys. 25, 739 (1987).

[10] M. Ballauff, Makromol. Chem., Rapid Commun. 7, 407 (1986)

[11] G. Wegner, Macromol. Chem. Phys. 204, 347 (2003).

[12] R. Stepanyan, A. Subbotin, and G. ten Brinke, Phys. Rev. E 63, 061805 (2001).

[13] S.-C. Yang, W. Graupner, S. Guha, P. Puschnig, C. Martin, H. R. Chandrasekhar, M. Chandrasekhar, G. Leising, C. Ambrosch-Draxl, and U. Scherf, Phys. Rev. Lett. 85, 2388 (2000).

[14] A. P. Monkman, H. D. Burrows, L. J. Hartwell, L. E. Horsburgh, I. Hamblett, and S. Navaratnam, Phys. Rev. Lett. 86, 1358 (2001).

[15] S. M. Yu and D. A. Tirrell, Biomacromolecules 1, 310 (2000).

[16] B. Guilleaume, J. Blaul, M. Ballauff, M. Wittemann, M. Rehahn, and G. Goerigk, Eur. Phys. J. E 8, 299 (2002).

[17] M. Patel, S. Rosenfeldt, M. Ballauff, N. Dingenouts, D. Pontoni, and T. Narayanan, Phys. Chem. Chem. Phys. 6, 2962 (2004).

[18] A. Gitsas, G. Floudas, and G. Wegner, Phys. Rev. E 69, 041802 (2004).

[19] M. J. Winokur, D. Spiegel, Y. Kim, S. Hotta, and A. J. Heeger, Synth. Met. 28, C419 (1989).

[20] E. J. Samuelsen and J. Mårdalen, in Handbook of Organic
Conductive Molecules and Polymers, edited by H. S. Nalwa (Wiley, New York, 1997), Vol. 3, p. 87.

[21] D. W. Breiby, E. J. Samuelsen, O. Konovalov, and B. Struth, Langmuir 20, 4116 (2004).

[22] H. Sirringhaus, P. J. Brown, R. H. Friend, M. M. Nielsen, K. Bechgaard, B. M. W. Langeveld-Voss, A. J. H. Spiering, R. A. J. Janssen, E. W. Meijer, P. Herwig, and D. M. de Leeuw, Nature (London) 401, 685 (1999).

[23] H. Sirringhaus, P. J. Brown, R. H. Friend, M. M. Nielsen, K. Bechgaard, B. M. W. Langeveld-Voss, A. J. H. Spiering, R. A. J. Janssen, and E. W. Meijer, Synth. Met. 111-112, 129 (2000).

[24] U. Scherf and E. J. W. List, Adv. Mater. (Weinheim, Ger.) 14, 477 (2002).

[25] M. Grell and D. D. C. Bradley, Adv. Mater. (Weinheim, Ger.) 11, 895 (1999).

[26] H. Sirringhaus, R. J. Wilson, R. H. Friend, M. Inbasekaran, W. Wu, E. P. Woo, M. Grell, and D. D. C. Bradley, Appl. Phys. Lett. 77, 406 (2000).

[27] L. Kinder, J. Kanicki, J. Swensen, and P. Petroff, Proc. SPIE 5217, 35 (2003).

[28] S. Kawana, M. Durrell, J. Lu, J. E. MacDonald, M. Grell, D. D. C. Bradley, P. C. Jukes, R. A. L. Jones, and S. L. Bennett, Polymer 43, 1907 (2002).

[29] A. Meisel, T. Miteva, G. Glaser, V. Scheumann, and D. Neher, Polymer 43, 5235 (2002).

[30] M. Surin, E. Hennebicq, C. Ego, D. Marsitzky, A. C. Grimsdale, K. Müllen, J.-L. Brédas, R. Lazzaroni, and P. Leclère, Chem. Mater. 16, 994 (2004).

[31] H. Cheun, B. Tanto, W. Chunwaschirasiri, B. Larson, and M. J. Winokur, Appl. Phys. Lett. 84, 22 (2004).

[32] B. Tanto, S. Guha, C. M. Martin, U. Scherf, and M. J. Winokur Macromolecules 37, 9438 (2004).

[33] M. J. Banach, R. H. Friend, and H. Sirringhaus, Macromolecules 37, 6079 (2004).

[34] M. Grell, D. D. C. Bradley, G. Ungar, J. Hill, and K. S. Whitehead, Macromolecules 32, 5810 (1999).

[35] M. J. Winokur, J. Slinker, and D. L. Huber, Phys. Rev. B 67, 184106 (2003)

[36] M. Grell, W. Knoll, D. Lupo, A. Meisel, T. Miteva, D. Neher, H.-G. Nothofer, U. Scherf, and A. Yasuda, Adv. Mater. (Wein- 
heim, Ger.) 11, 671 (1999).

[37] H.-G. Nothofer, A. Meisel, T. Miteva, D. Neher, M. Forster, M. Oda, G. Lieser, D. Sainova, A. Yasuda, D. Lupo, W. Knoll, and U. Scherf, Macromol. Symp. 154, 139 (2000).

[38] R. W. T. Higgins, A. P. Monkman, H.-G. Nothofer, and U. Scherf, J. Appl. Phys. 91, 99 (2002).

[39] B. P. Lyons, K. S. Wong, and A. P. Monkman, J. Chem. Phys. 118, 4707 (2003).

[40] H. A. Al Attar, A. P. Monkman, M. Tavasli, S. Bettington, and M. R. Bryce, Appl. Phys. Lett. 86, 121101 (2005).

[41] T. Miteva, A. Meisel, H.-G. Nothofer, U. Scherf, W. Knoll, D. Neher, M. Grell, D. Lupo, and A. Yasuda, Proc. SPIE 3797, 231 (1999).

[42] S. Sinha, C. Rothe, R. Güntner, U. Scherf, and A. P. Monkman, Phys. Rev. Lett. 90, 127402 (2003).

[43] G. Lieser, M. Oda, T. Miteva, A. Meisel, H.-G. Nothofer, U. Scherf, and D. Neher, Macromolecules 33, 4490 (2000).

[44] G. W. Heffner, S. J. Dahman, D. S. Pearson, and C. L. Gettinger, Polymer 34, 3155 (1993).

[45] R. J. Kline, M. D. McGehee, E. N. Kadnikova, J. Liu, and J. M. J. Frechet, Adv. Mater. (Weinheim, Ger.) 15, 1519 (2003).

[46] A. Zen, J. Pflaum, S. Hirschmann, W. Zhuang, F. Jaiser, U. Asawapirom, J. P. Rabe, U. Scherf, and D. Neher, Adv. Funct. Mater. 14, 757 (2004).

[47] H. J. Snaith and R. H. Friend, Thin Solid Films 451-452, 567 (2004).

[48] K.-H. Weinfurtner, H. Fujikawa, S. Tokito, and Y. Taga, Appl. Phys. Lett. 76, 2502 (2000).

[49] K. Hosoi, T. Mori, T. Mizutani, T. Yamamoto, and N. Kitamura, Thin Solid Films 438-439, 201 (2003).

[50] P. Papadopoulos, G. Floudas, C. Chi, and G. Wegner, J. Chem. Phys. 120, 2368 (2004).

[51] M. J. Banach, R. H. Friend, and H. Sirringhaus, Macromolecules 36, 2838 (2003).

[52] M. Knaapila, B. P. Lyons, K. Kisko, J. P. Foreman, U. Vainio, M. Mihaylova, O. H. Seeck, L.-O. Pålsson, R. Serimaa, M. Torkkeli, and A. P. Monkman, J. Phys. Chem. B 107, 12425 (2003).

[53] M. Knaapila, K. Kisko, B. P. Lyons, R. Stepanyan, J. P. Foreman, O. H. Seeck, U. Vainio, L.-O. Pålsson, R. Serimaa, M. Torkkeli, and A. P. Monkman, J. Phys. Chem. B 108, 10711 (2004).

[54] M. Knaapila, B. P. Lyons, K. Kisko, O. H. Seeck, J. P. Foreman, U. Vainio, R. Serimaa, M. Torkkeli, and A. P. Monkman, Proc. SPIE 5519, 226 (2004).

[55] B. P. Lyons and A. P. Monkman, J. Appl. Phys. 96, 4735 (2004).
[56] D. Chen, M. J. Winokur, M. A. Masse, and F. E. Karasz, Polymer 33, 3116 (1992).

[57] K. E. Aasmundtveit, E. J. Samuelsen, M. Guldstein, C. Steinsland, O. Flornes, C. Fagermo, T. M. Seeberg, L. A. A. Pettersson, O. Inganäs, R. Feidenhans'l, and S. Ferrer, Macromolecules 33, 3120 (2000).

[58] T. J. Prosa, M. J. Winokur, J. Moulton, P. Smith, and A. J. Heeger, Macromolecules 25, 4364 (1992).

[59] G. Fytas, H. G. Nothofer, U. Scherf, D. Vlassopoulos, and G. Meier, Macromolecules 35, 481 (2002).

[60] M. Knaapila, R. Stepanyan, B. P. Lyons, M. Torkkeli, T. P. A. Hase, R. Serimaa, R. Güntner, O. H. Seeck, U. Scherf, and A. P. Monkman Macromolecules 38, 2744 (2005).

[61] R. Stepanyan, A. Subbotin, M. Knaapila, O. Ikkala, and G. ten Brinke, Macromolecules 36, 3758 (2003).

[62] A. Subbotin, R. Stepanyan, M. Knaapila, O. Ikkala, and G. ten Brinke, Eur. Phys. J. E 12, 333 (2003).

[63] M. Knaapila, R. Stepanyan, L. E. Horsburgh, A. P. Monkman, R. Serimaa, O. Ikkala, A. Subbotin, M. Torkkeli, and G. ten Brinke, J. Phys. Chem. B 107, 14199 (2003).

[64] A. N. Semenov, Sov. Phys. JETP 61, 733 (1985).

[65] L. Rosta, Appl. Phys. A: Mater. Sci. Process. 74, S52 (2002).

[66] T. C. Huang, H. Toraya, T. N. Blanton, and Y. Wu, J. Appl. Crystallogr. 26, 180 (1993).

[67] R. D. B. Fraser, T. P. MacRae, and E. Suzuki, J. Appl. Crystallogr. 11, 693 (1978).

[68] V. F. Sears, Neutron News 3, 29 (1992).

[69] M. Tammer, R. W. T. Higgins, and A. P. Monkman, J. Appl. Phys. 91, 4010 (2002).

[70] M. Grell, D. D. C. Bradley, M. Inbasekaran, G. Ungar, K. S. Whitehead, and E. P. Woo, Synth. Met. 111-112, 579 (2000).

[71] W. Chunwaschirasiri, B. Tanto, D. L. Huber, and M. J. Winokur, Phys. Rev. Lett. 94, 107402 (2005).

[72] Yu. D. Zaroslov, V. I. Gordeliy, A. I. Kuklin, A. H. Islamov, O. E. Philippova, A. R. Khokhlov, and G. Wegner, Macromolecules 35, 4466 (2002).

[73] P. Hickl, M. Ballauff, U. Scherf, K. Müllen, and P. Lindner, Macromolecules 30, 273 (1997).

[74] D. Wang, J. Lal, D. Moses, G. C. Bazan, and A. J. Heeger, Chem. Phys. Lett. 348, 411 (2001).

[75] S. I. Hintschich, C. Rothe, S. Sinha, A. P. Monkman, P. Scandiucci de Freitas, and U. Scherf, J. Chem. Phys. 119, 12017 (2003).

[76] H.-G. Nothofer, Ph.D. thesis, MathematischNaturwissenschaftliche Fakultät, Universität Potsdam, Berlin, 2001. 